\title{
Upper layer current variability in the Central Ligurian Sea
}

\author{
P. Picco ${ }^{1}$, A. Cappelletti ${ }^{2}$, S. Sparnocchia ${ }^{3}$, M. E. Schiano ${ }^{4}$, S. Pensieri ${ }^{5}$, and R. Bozzano \\ ${ }^{1}$ ENEA CRAM, Forte S. Teresa, 19036 Pozzuolo di Lerici (SP), Italy \\ ${ }^{2}$ ENEA, Via V. Viviani 23, 56124 Pisa, Italy \\ ${ }^{3}$ CNR-ISMAR-TS, Viale R. Gessi 2, 34123 Trieste, Italy \\ ${ }^{4}$ CNR ISMAR-GE, Via de Marini 6, 16149 Genova, Italy \\ ${ }^{5}$ CNR ISSIA-GE, Via de Marini 6, 16149 Genova, Italy
}

Received: 20 January 2010 - Published in Ocean Sci. Discuss.: 9 March 2010

Revised: 17 September 2010 - Accepted: 20 September 2010 - Published: 1 October 2010

\begin{abstract}
Long-time series of surface currents and meteorological parameters were analysed to estimate the variability of the upper layer circulation and the response to the local winds. Current meter data were collected by an upward-looking RDI Sentinel $300 \mathrm{kHz}$ ADCP deployed in the Central Ligurian Sea $\left(43^{\circ} 47.77^{\prime} \mathrm{N} ; 9^{\circ} 02.85^{\prime} \mathrm{E}\right)$ near the meteo-oceanographic buoy ODAS Italia 1 for more than eight months, from 13th of September 2003 to 24th of May 2004. The ADCP sampled the upper $50 \mathrm{~m}$ of water column at $8 \mathrm{~m}$ vertical resolution and $1 \mathrm{~h}$ time interval; surface marine and atmospheric hourly averaged data were provided by the buoy. Currents in the sampled layer were mainly barotropic, directed North-West in accordance with the general circulation of the area, and had a mean velocity of about $18 \mathrm{~cm} / \mathrm{s}$ and hourly mean peaks up to $80 \mathrm{~cm} / \mathrm{s}$. Most of the observed variability in the upper thermocline was determined by inertial currents and mesoscale activity due to the presence of the Ligurian Front. Local wind had a minor role in the nearsurface circulation but induced internal waves propagating downward in the water column.
\end{abstract}

\section{Introduction}

The general circulation of the Ligurian basin is relatively well-known as it has been the subject of detailed research since the 1960s (Ovchinnikov, 1966). It is characterized by a cyclonic gyre involving both the surface Modified Atlantic Water (MAW) and the lower Levantine Intermediate Water

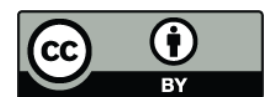

Correspondence to: P. Picco

(paola.picco@enea.it)
(LIW) (Millot, 1987). The cyclonic circulation affects the hydrological structure of the basin, giving rise to three distinct zones: the coastal peripheral, the frontal and the central ones. The frontal zone divides the warmer and lighter coastal waters from the colder and denser waters of the central zone (Sournia et al., 1990). The two main current systems entering the Ligurian Sea - the Western Corsica Current and the Eastern Corsica Current - join north of Cape Corse, giving origin to the so-called Northern Current, or Ligurian-Provençal Current, which flows along the Ligurian and French coasts (Millot, 1991). Although this structure is almost permanent, it shows an important seasonal and inter-annual variability, with more intense currents during winter period (Astraldi and Gasparini, 1992) and intense mesoscale activity related to the strong frontal system, as also detected by remote and in situ observations (Vignudelli et al., 2000; Birol et al., 2010).

Despite the intensive investigations in the coastal Ligurian Sea (Astraldi and Manzella, 1983), only few studies focused on the variability at shorter time-space scale due to the lack of devoted observations in the open sea.This background knowledge can be of advantage in many fields, which span from the setting up of appropriate monitoring networks to the improvement of forecasting models and high-resolution oceanic prediction systems.

In order to investigate the surface current variability and its response to the local atmospheric forcing, a mooring equipped with an upward-looking Acoustic Doppler Current Profiler (ADCP) and conductivity-temperature-depth (CTD) devices was deployed on 13th of September 2003, offshore, near the meteo-oceanographic buoy ODAS Italia 1 (Picco et al., 2007) and recovered on 24th of May 2004.

The results of the analysis of the long-time series of data collected from both mooring and buoy are given in this paper.

Published by Copernicus Publications on behalf of the European Geosciences Union. 
The paper is organized as follow: Sect. 2 presents the experimental set-up and the available data. A brief description of the meteorological and hydrological conditions occurring during the examined period is reported in Sect. 3. In Sect. 4 the surface currents are investigated by using both Empirical Orthogonal Function (EOF) and time-frequency analysis, while Sect. 5 focuses on the effects of local wind. The main findings are summarized in Sect. 6.

\section{Instrumentation and data}

ADCP current data were collected by an oceanographic mooring deployed in the Central Ligurian Sea $\left(43^{\circ} 47.77^{\prime} \mathrm{N}\right.$; $\left.9^{\circ} 02.85^{\prime} \mathrm{E}\right)$ at $1040 \mathrm{~m}$ depth from 13th of September 2003 to 24th of May 2004. The mooring was equipped with an upward-looking broadband RDI $300 \mathrm{kHz}$ ADCP located at $58 \mathrm{~m}$ depth and with two temperature and conductivity devices (SeaCat 37 from Sea-Bird Electronics Inc.) installed at $68 \mathrm{~m}$ and $250 \mathrm{~m}$ depth. The device at $68 \mathrm{~m}$ depth was also equipped with a pressure sensor to monitor its effective depth, but unfortunately a failure occurred on 11th of April 2004 before the end of the experiment.

The ADCP was set-up at 8-m vertical resolution; the middepth of the first bin cell was at $48 \mathrm{~m}$ and the last (bin 6) at $8 \mathrm{~m}$, close to the sea-surface. The sampling time interval was $1 \mathrm{~h}$ and each data ensemble was the average of 55 pings. This set-up configuration leads to a nominal error of $0.23 \mathrm{~cm} / \mathrm{s}$ on the horizontal currents, according to the instrument's specifications. The vertical displacement of the mooring was checked using both the pressure measurements from the CTD device and the distance of the ADCP from the water surface computed according to Visbeck and Fischer (1995). The two estimations were in good agreement and indicated that the mooring was generally stable: vertical displacements higher than $4 \mathrm{~m}$ occurred only during a few short events. Pitch and roll data never exceeded $2.5^{\circ}$, thus they always remained below the threshold of $9^{\circ}$ for valid tilt compensation. Echo amplitude, which describes the relative strength of the backscattered signal, was strong enough to maintain the signal/noise ratio above 10 during almost all the period of measurements according to common quality standard (Schott and Leaman, 1991). The mean profile had a maximum for bin 6 , and some attenuation with the distance from the instrument. Percentage of good data was always near to $100 \%$, so there was no need to discard any data.

Meteorological data were provided by the open sea laboratory ODAS Italia 1. It is a spar meteo-oceanographic buoy specifically developed for air-sea interaction studies and equipped to collect meteorological and marine data. In the period referred to, it was moored about 40 nautical miles offshore, in the Central Ligurian Sea $\left(43^{\circ} 47.28^{\prime} \mathrm{N}\right.$; $9^{\circ} 09.78^{\prime} \mathrm{E}$ ) at $1440 \mathrm{~m}$ depth (Fig. 1). Two complete sets of meteorological sensors were installed on the top of the buoy at a height of $13.5 \mathrm{~m}$. In order to collect sea temperatures and

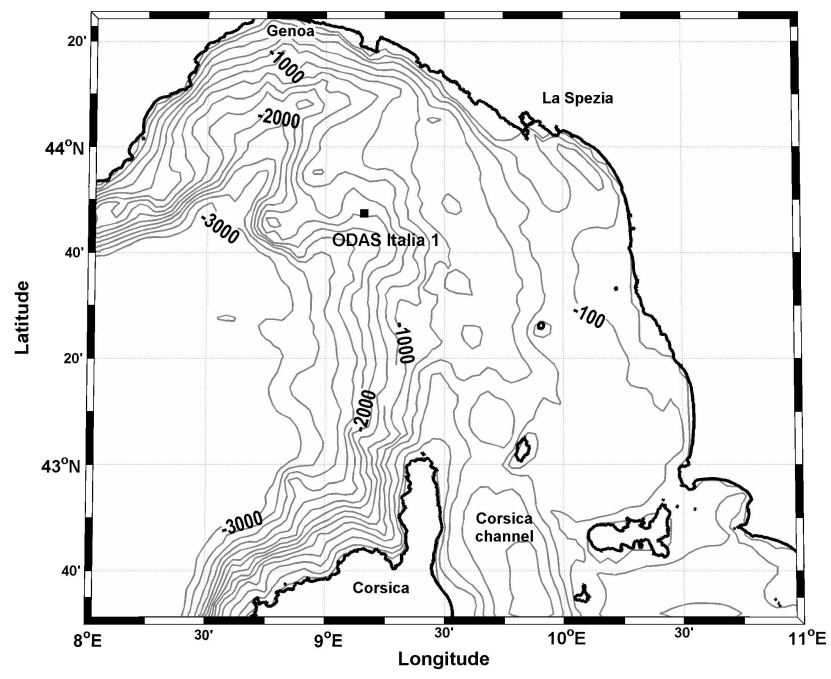

Fig. 1. Map of the Ligurian Sea with the bathimetry. A dot marks the location of the ODAS Italia1 buoy and the mooring.

salinity data, marine sensors were mounted along the body of the buoy at various depths (see Table 1 for instrumental details). Meteorological parameters were collected by the onboard acquisition system every $5 \mathrm{~s}$, while the marine devices took a sample every $30 \mathrm{~min}$. All the collected data were stored onboard and transmitted periodically to the receiving station ashore. The buoy operated regularly from 13th of September 2003 to 8th of March 2004, when the acquisition system failed. Only two interruptions, lasting a couple of hours and due to maintenance activities to the buoy equipment, occurred during that period and the resulting short gaps were filled with interpolated data. Apart from the above mentioned failure of the pressure sensor, all the devices located on the mooring properly worked until they were recovered on 24th of May 2004. CTD devices were calibrated at the laboratory of NATO Undersea Research Centre (NURC) in La Spezia before their use.

Additional CTD profiles were performed during two oceanographic campaigns for the mooring deployment and recovery operations on September 2003 and April-May 2004.

\section{Meteorological and hydrological conditions}

Hydrological conditions were inferred from the measurements of conductivity and temperature acquired by the sensors deployed on the buoy and on the mooring, and from the CTD profiles performed during the oceanographic campaigns.

The seasonal evolution of the upper layer during the period of measurements included the late summer stratification, the thermocline erosion, the winter mixing and the formation of weak early spring stratification. The vertical structure, as 
Table 1. Details of the instruments deployed on the ODAS Italia1 buoy and on the mooring and the used equipment of the N/O Urania. The table shows for each parameter: the instruments used for the measurements, the platform on which they were installed, the depth/height of the devices, and the working period.

\begin{tabular}{|c|c|c|c|c|}
\hline Parameter & Instrument & Platform & Height/Depth & From/To \\
\hline Wind speed & $\begin{array}{l}\text { Th. Friedrichs } \\
4020\end{array}$ & buoy & $13.5 \mathrm{~m}$ & $13 / 09 / 2003-8 / 03 / 2004$ \\
\hline $\begin{array}{l}\text { Wind } \\
\text { direction }\end{array}$ & $\begin{array}{l}\text { Th. Friedrichs } \\
4121\end{array}$ & buoy & $13.5 \mathrm{~m}$ & $13 / 09 / 2003-8 / 03 / 2004$ \\
\hline $\begin{array}{l}\text { Atmospheric } \\
\text { pressure }\end{array}$ & $\begin{array}{l}\text { Th. Friedrichs } \\
5006\end{array}$ & buoy & $12.5 \mathrm{~m}$ & $13 / 09 / 2003-8 / 03 / 2004$ \\
\hline $\begin{array}{l}\text { Sea temperature } \\
\text { and conductivity }\end{array}$ & $\begin{array}{l}\text { Sea-Bird Electronics } \\
\text { Inc. SBE37, SBE } 39\end{array}$ & buoy & $\begin{array}{l}-0.5,-6,-12,-20 \\
-28,-35 \mathrm{~m}\end{array}$ & $13 / 09 / 2003-8 / 03 / 2004$ \\
\hline $\begin{array}{l}\text { Sea temperature } \\
\text { and conductivity }\end{array}$ & $\begin{array}{l}\text { Sea-Bird Electronics } \\
\text { Inc. SBE37 }\end{array}$ & mooring & $-70,-250 \mathrm{~m}$ & $13 / 09 / 2003-24 / 05 / 2004$ \\
\hline 3-D currents & $\begin{array}{l}\text { ADCP RDI } \\
300 \mathrm{kHz}\end{array}$ & mooring & $0,-48 \mathrm{~m}(d z=8 \mathrm{~m})$ & $13 / 09 / 2003-24 / 05 / 2004$ \\
\hline $\begin{array}{l}\text { Sea temperature } \\
\text { and conductivity }\end{array}$ & SBE 19 & N/O Urania & $\begin{array}{l}\text { Profile from } 0 \text { down } \\
\text { to } 200 \mathrm{~m}\end{array}$ & $11-13 / 09 / 2003$ 26/04/2004 \\
\hline
\end{tabular}

deduced from CTD profiles taken during the mid September cruise (Fig. 2) can be described as a two layer system with the sharp thermocline located around 35-40 m depth, at the same depth of the subsurface summer minimum salinity (37.85 psu). The upper $25-30 \mathrm{~m}$ layer was quite well mixed having $22.5^{\circ} \mathrm{C}$ temperature and 38.3 psu salinity. Summer 2003 was one of the hottest in recent years (Sparnocchia et al., 2006) and in September the sea surface temperature was still very high. Below the thermocline the temperature was near $13.5^{\circ} \mathrm{C}$. Until late autumn, temperature and salinity time series at $35 \mathrm{~m}$ depth (Fig. 3) showed variations up to $6^{\circ} \mathrm{C}$ and $0.3 \mathrm{psu}$, respectively, indicating the presence of the colder and fresher waters alternating with warmer and saltier. These episodes lasting up to several days can be associated to the mesoscale dynamics of the front separating the coastal from the open-sea waters. Mesoscale structures close to the mooring location were evidenced by both sea surface temperature (SST) satellite images (Fig. 4) and by CTD profiles performed between the mooring location and the coast on 11th of September 2003 (Fig. 5). Temperature and salinity vertical section depicted a marked horizontal variability in the upper thermocline (0-50 m) and the computed geostrophic currents indicated rotations and meandering. This variability is a typical feature of summer circulation in the area as already reported by different authors (Astraldi et al., 1990) and, more recently, investigated by means of satellite altimetry observations and ADCP measurements by Birol et al. (2010). Mixed layer reached the depth of $35 \mathrm{~m}$ at the end of October, as a result of the mixing due to an intense (higher than $18 \mathrm{~m} / \mathrm{s}$ ) westerly wind event. Winter homogeneity was completely developed from mid February, when temperature was below $14^{\circ} \mathrm{C}$, salinity was quite uniform around 38.2 psu in the upper $70 \mathrm{~m}$ and density had the minimum vertical gradient. Winter SST image (Fig. 4b) showed an enhancement of the cyclonic gyre, having colder waters in the central part. This situation was still persisting at the beginning of March, when the conductivity and temperature sensors installed on the buoy stopped working. CTD profiles performed on 26th of April 2004 indicated an early thermocline formation due to surface warming: the upper $10 \mathrm{~m}$ had a temperature of $16^{\circ} \mathrm{C}$ and a weak thermal gradient had started developing. Salinity still had the minimum at the surface ( $37.88 \mathrm{psu}$ ) and it increased with depth, reaching $38.37 \mathrm{psu}$ at $250 \mathrm{~m}$ depth.

Wind was generally low: values lower than $5 \mathrm{~m} / \mathrm{s}$ (force 3 ) occurred in the $50 \%$ of the cases. Both wind speed and direction showed high variability (Fig. 6): mean speed on the whole period of observation was $6.2 \mathrm{~m} / \mathrm{s}$ and the standard deviation was $4.1 \mathrm{~m} / \mathrm{s}$. Wind strength greater than $13 \mathrm{~m} / \mathrm{s}$ (force 7) occurred only $5 \%$ of the time and, generally, during the passage of significant low pressure systems (minimum below $1000 \mathrm{hPa}$ ) with westerly wind. The maximum hourly mean value $(23.3 \mathrm{~m} / \mathrm{s})$ was recorded on 5 th of October 2003 when the pressure dropped to $995 \mathrm{hPa}$. Only in a few cases the high wind persisted longer than $48 \mathrm{~h}$, as it occurred, for example, in the period from 22nd to 24th of January 2004 when the wind was blowing from North-East at a speed higher than $10 \mathrm{~m} / \mathrm{s}$. Spectral analysis of the wind time series was computed on 256-h long samples, which were then averaged. The spectrum was generally noisy and peaks were not well resolved. Thus any significant periodicity was not clearly 

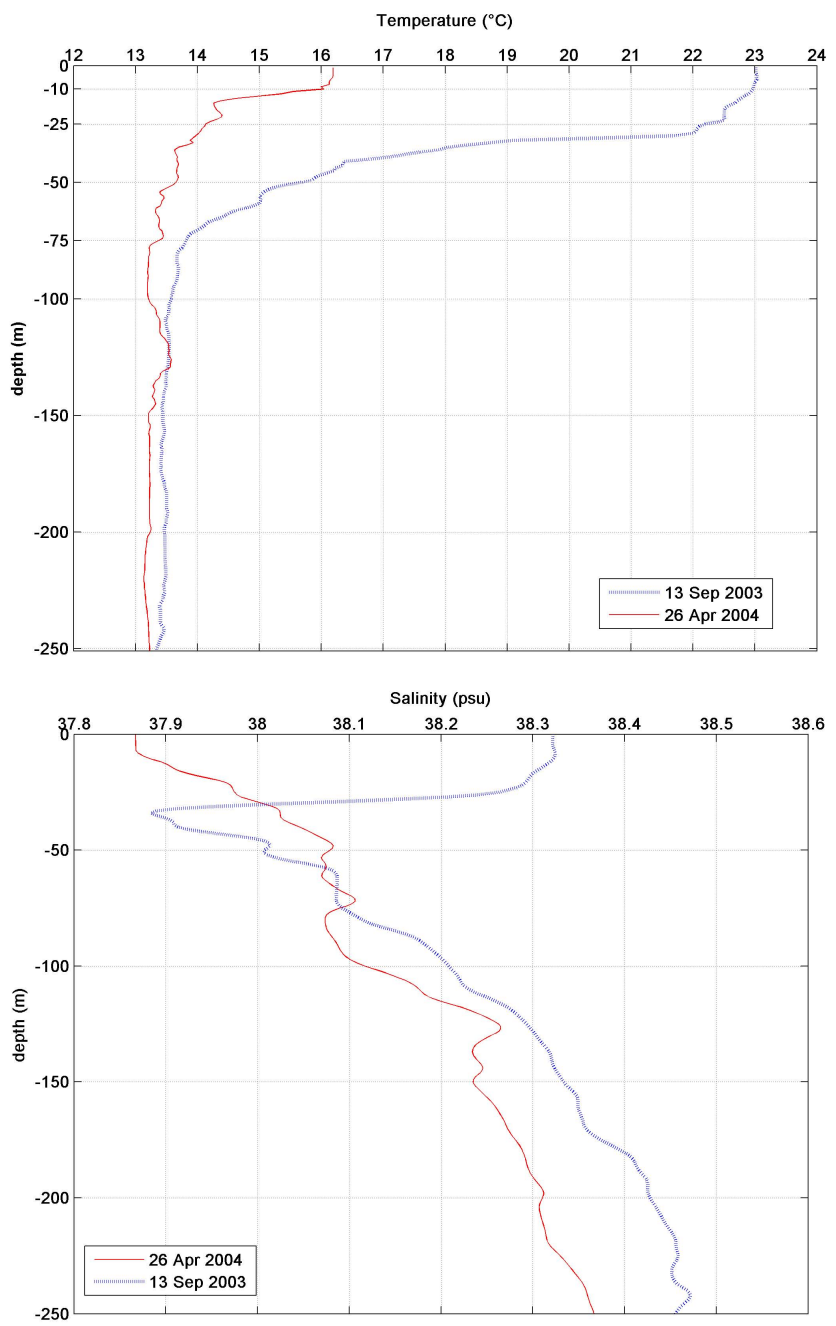

Fig. 2. Temperature (a) and Salinity (b) profiles taken on 13th of September 2003 and 26th of April 2004 close to the ODAS Buoy.

reveal except from few energy peaks on the diurnal band that can be ascribed to the breeze regime. In order to investigate a lower frequency part of the signal, the analysis was also performed on 1024-h long samples. Peaks centred respectively on $58 \mathrm{~h}$ and $95 \mathrm{~h}$ were evidenced and most of the energy was also found in the 100-140 $\mathrm{h}$ band and on $210 \mathrm{~h}$.

\section{Currents analysis}

\subsection{General description}

Stick diagrams and progressive vectors of daily mean horizontal currents reported respectively in Figs. 7 and 8 allowed to describe their temporal evolution during the period of observation. The currents were almost vertically homogeneous, having the same pattern but attenuating with depth: the mean speed decreased with depth from $20.8 \mathrm{~cm} / \mathrm{s}$ in the surface layer to $13.9 \mathrm{~cm} / \mathrm{s}$ at $48 \mathrm{~m}$ (Table 2). They were mainly di-
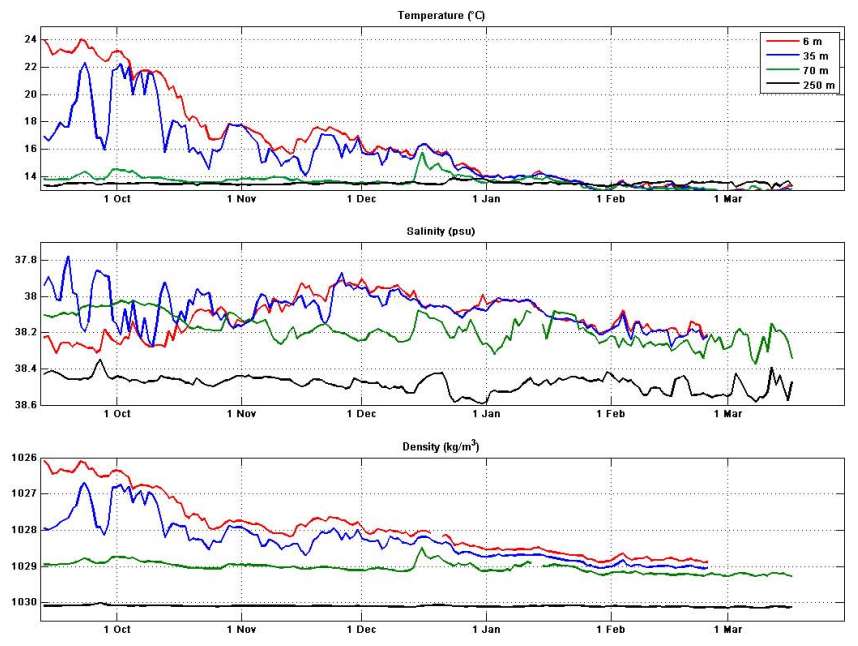

Fig. 3. Time series of daily mean data of sea temperature, salinity and density from 13th of September 2003 to 8th of March 2004 at $5 \mathrm{~m}, 36 \mathrm{~m}, 68 \mathrm{~m}$, and $250 \mathrm{~m}$ depth. Data at 5 and $35 \mathrm{~m}$ were collected from the sensors located on ODAS Buoy, the others from those located on the mooring.

rected North-West, following the general cyclonic circulation of the Ligurian Sea. The flow was North-East shifted by meanderings associated to the mesoscale activity with a periodicity of about ten days. Currents directed to the South were observed only during a few short episodes; they had a lower intensity and were mainly confined to the near-surface layer, where meandering and rotations were more developed (Fig. 9). This difference in the pattern was consistent with the results of the complex correlation analysis (Table 3) which reports lower value coefficients in the first column.

\subsection{Empirical Orthogonal Function analysis}

Complex Empirical Orthogonal Function (EOF) analysis was performed on the time series of current profiles. Spatial EOF decomposition (Emery and Thomson, 2001) is often used to analyse geophysical data characterized by a spatial pattern in this case the ADCP current profile - evolving with time. The profile at each temporal step is represented as a linear combination of a limited number of profiles (modes) which can be associated to different dynamical mechanisms; the coefficients of the linear combination indicate the relative importance of each mode.

Following Björnsson and Venegas (1995), the EOFs were obtained using the singular value decomposition (SVD) method.

Let $\mathbf{C}(N, K)$ the data matrix where $N$ is the number of samples and $K$ is the number of the vertical levels of each profile the data matrix. $\mathbf{R}$ is

$$
\mathbf{R}=\mathbf{C}^{\mathrm{H}} \mathbf{C}
$$


Table 2. General statistics of currents for each level of the profile: mean velocities in Cartesian (East and North components with standard deviation) and Polar (intensity and direction) coordinates; mean of velocity intensities with relative standard deviation and maximum.

\begin{tabular}{|c|c|c|c|c|c|c|c|}
\hline & & \multicolumn{6}{|c|}{ Levels of the ADCP } \\
\hline & & $8 \mathrm{~m}$ & $16 \mathrm{~m}$ & $24 \mathrm{~m}$ & $32 \mathrm{~m}$ & $40 \mathrm{~m}$ & $48 \mathrm{~m}$ \\
\hline \multirow{4}{*}{ Cartesian coordinates } & East $(\mathrm{cm} / \mathrm{s})$ & -5.3 & -5.7 & -5.3 & -5.0 & -4.7 & -4.6 \\
\hline & Std & 15.4 & 13.8 & 12.7 & 11.6 & 10.7 & 9.6 \\
\hline & North $(\mathrm{cm} / \mathrm{s})$ & 8.7 & 11.3 & 10.8 & 9.9 & 9.0 & 8.2 \\
\hline & Std & 14.7 & 12.4 & 11.4 & 10.4 & 9.3 & 8.4 \\
\hline \multirow{5}{*}{ Polar coordinates } & Intensity $(\mathrm{cm} / \mathrm{s})$ & 10.2 & 12.6 & 12.0 & 11.1 & 10.1 & 11.3 \\
\hline & Direction $\left({ }^{\circ} \mathrm{N}\right)$ & 328 & 333 & 334 & 333 & 332 & 330 \\
\hline & Mean intensity $(\mathrm{cm} / \mathrm{s})$ & 20.8 & 19.7 & 18.3 & 16.9 & 15.4 & 13.9 \\
\hline & Std & 11.3 & 11.0 & 10.0 & 9.1 & 8.2 & 7.7 \\
\hline & $\operatorname{Max}$ & 82.7 & 63.1 & 56.8 & 52.8 & 49.7 & 42.8 \\
\hline
\end{tabular}

Table 3. Complex correlation coefficient matrix of horizontal currents: absolute values are shown in the lower-left part whereas angles in degree are in the upper-right portion of the table.

\begin{tabular}{l|cccccc}
\hline & $8 \mathrm{~m}$ & $16 \mathrm{~m}$ & $24 \mathrm{~m}$ & $32 \mathrm{~m}$ & $40 \mathrm{~m}$ & $48 \mathrm{~m}$ \\
\hline $8 \mathrm{~m}$ & & 2.3 & 4.4 & 5.8 & 6.4 & 4.7 \\
$16 \mathrm{~m}$ & 0.80 & & 2.5 & 4.0 & 4.5 & 3.6 \\
$24 \mathrm{~m}$ & 0.74 & 0.97 & & 2.2 & 3.0 & 2.8 \\
$32 \mathrm{~m}$ & 0.67 & 0.88 & 0.95 & & 1.5 & 2.8 \\
$40 \mathrm{~m}$ & 0.60 & 0.80 & 0.85 & 0.95 & & 3.0 \\
$48 \mathrm{~m}$ & 0.55 & 0.71 & 0.77 & 0.86 & 0.95 & \\
\hline
\end{tabular}

Using the SVD method

$\mathbf{R U}=\mathbf{U S}$

where $\mathbf{U}$ is the eigenvectors complex matrix, and $\mathbf{S}$ is the eigenvalues diagonal real matrix.

Due to the property $\mathbf{U}^{\mathrm{H}}=\mathbf{U}^{-1}$ the Eq. (2) can be transformed in:

$\mathbf{R}=\mathbf{U S V}$

where $\mathbf{V}=\mathbf{U}^{\mathrm{H}}$ (Björnsson and Venegas, 1997).

The temporal series of mode coefficients, $\mathbf{A}$, is given by:

$\mathbf{A}=\mathbf{C U}^{\mathrm{H}}$

The signal is then reconstructed by a linear combination of mode coefficients and mode profiles:

$\mathbf{C}_{\mathrm{EOF}}=\mathbf{A} \mathbf{U}^{\mathrm{H}}$

The temporal series of each mode currents is obtained by:

$\mathbf{C}_{\mathrm{EOF}_{\mathrm{m}}}=\mathbf{U}_{m}^{\mathrm{H}}$

Where $\mathbf{A}_{m}(N \times 1)$ and $\mathbf{U}_{m}(K \times 1)$ are the mth column of matrices $\mathbf{A}$ and $\mathbf{U}$.
This allows to separately analyzing the contribution of each mode to the original signal.

The relative importance of each mode is estimated by the weight:

$w_{k}=\frac{\mathbf{S}_{k, k}}{\operatorname{trace}(\mathbf{S})} 100 ; \quad k=1 . . K$

where $\mathbf{S}_{k}$ is the generic diagonal element of $\mathbf{S}$.

Experimental results have shown that a few EOFs are generally enough to model the original signal with a good accuracy (e.g. Hisaki, 2006; Edwards and Seim, 2008; Cappelletti et al, 2010). The first two mode profiles and the temporal evolution of mode coefficients are reported in figure 10. On the average, the first mode accounts for $94 \%$ of the total signal, the second for $4 \%$ and the third only for $1 \%$, so that the first three modes are able to reconstruct $99 \%$ of the entire signal. The first mode profile showed a barotropic structure, while the second mode described the surface variability, characterized by the highest velocities in the upper layer and negligible values in the other layers. The temporal evolution of each mode current was then reconstructed by using the modes profile and the coefficient time series. The first mode currents had a mean intensity decreasing from $18 \mathrm{~cm} / \mathrm{s}$ at $16 \mathrm{~m}$ depth down to $15 \mathrm{~cm} / \mathrm{s}$ at $48 \mathrm{~m}$. Near surface current intensity is lower $(13.9 \mathrm{~cm} / \mathrm{s})$ than in the layers below, but it is compensated by the second mode, which reaches the maximum $(11 \mathrm{~cm} / \mathrm{s})$ at surface.

In a few cases the second mode current was higher than the first mode, in particular during the periods from 8th-13th of November 2003 and from 23rd-25th of February 2004, in the presence of a southern current (Fig. 9).

The progressive vectors of each mode currents in the surface layer (Fig. 11) evidence the different patterns of the two modes. The first mode is by far prevailing over the examined period and describes the typical north-western general circulation of the area. Second mode surface currents displayed 

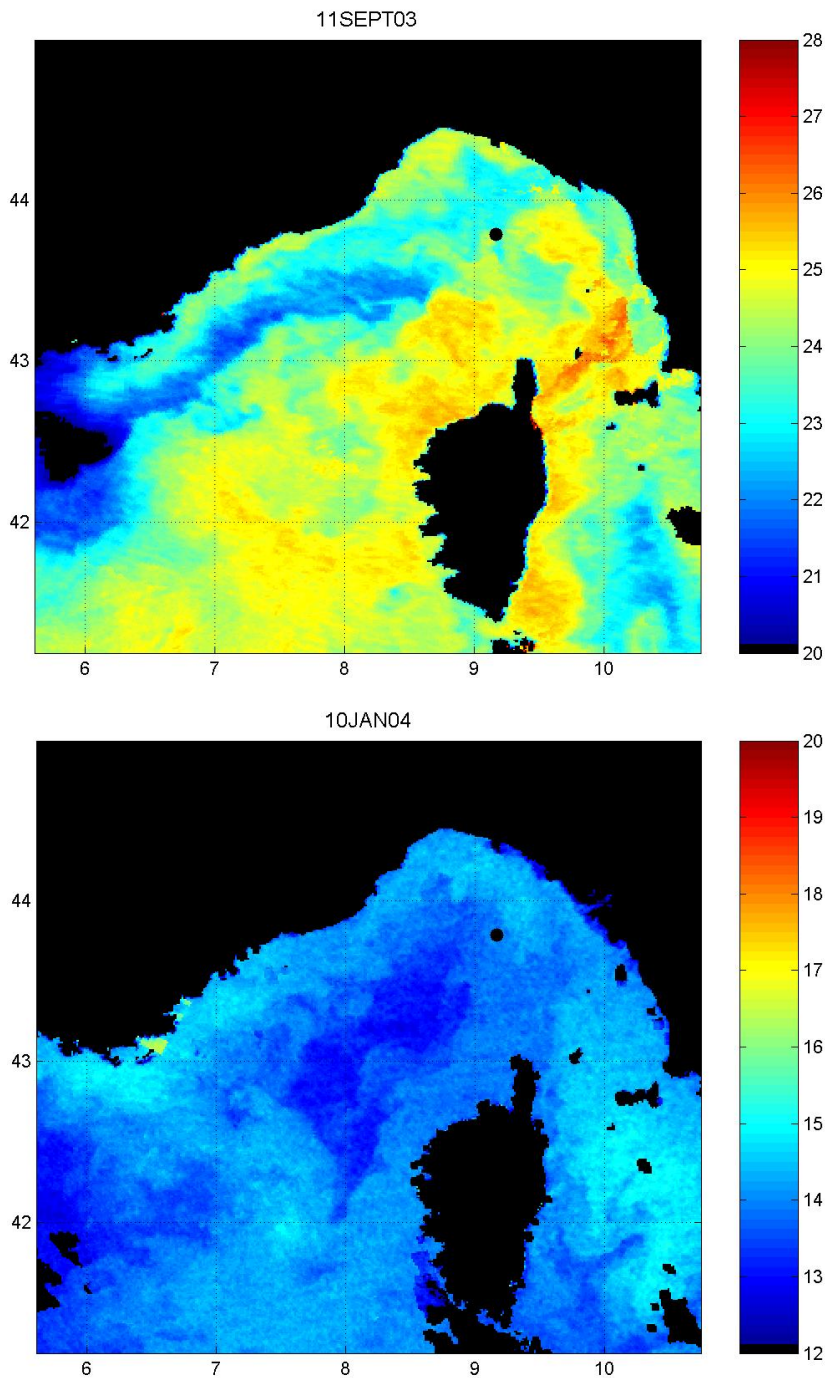

Fig. 4. SST images of the Ligurian Sea taken on 11th of September 2003 (a) and 10th of January 2004 (b). The image of September clearly evidences the front separating the peripheral coastal water from the water of the central zone. Winter SST indicates an enhancement of the cyclonic gyre, with colder waters in the central part. Big dot indicates the ODAS Buoy location.

an irregular pattern with sudden inversions and complete rotations; they were mainly directed to West until mid January, then they shifted toward South-East.

\subsection{Time-frequency analysis}

Rotary spectral analysis according to Gonella (1972) was carried out on current time series at each of the six levels.

To investigate the sub-diurnal band, complex FFT analysis was performed on 23 samples 256 -h long which were then averaged. Before the analysis, each sample was smoothed in order to limit the effect of the finite-length of the time series, which concentrates energy at the lowest frequency compo-
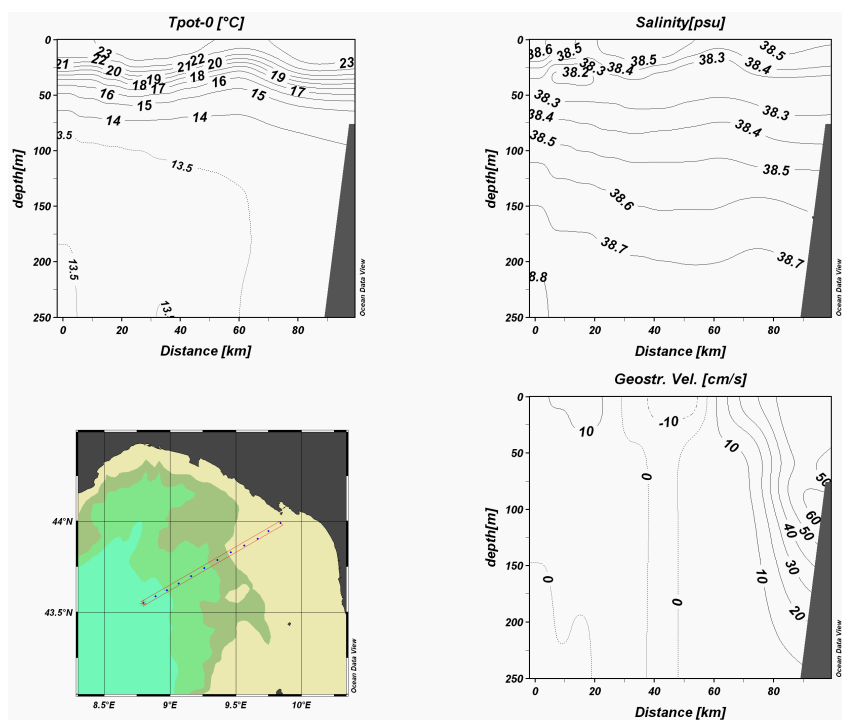

Fig. 5. CTD transect between the Ligurian coasts and the mooring location taken on 11th of September 2003. Dotted lines indicate the location of CTD profiles. Potential temperature, salinity and computed geostrophic currents evidence the mesoscale structures associated to the front.

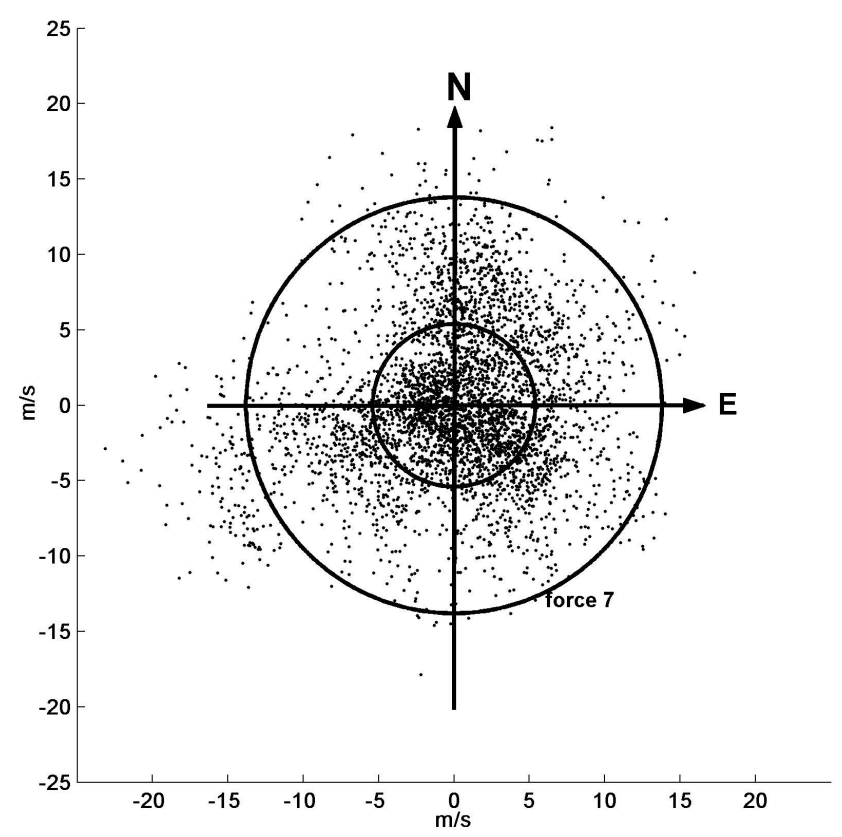

Fig. 6. Scatter plot of hourly wind speed data. Most of the data are concentrated inside the first circle indicating wind speed values below force 3 .

nents; then it was detrended to reduce the high-frequency noise. All the six spectra were by far dominated by the inertial frequency, which, at this latitude, is $0.0578 \mathrm{cph}$ (or $17.3 \mathrm{~h}$ period). The inertial peak had the maximum amplitude $(10.8 \mathrm{~cm} / \mathrm{s})$ at the second level and decreased to $6.7 \mathrm{~cm} / \mathrm{s}$ 


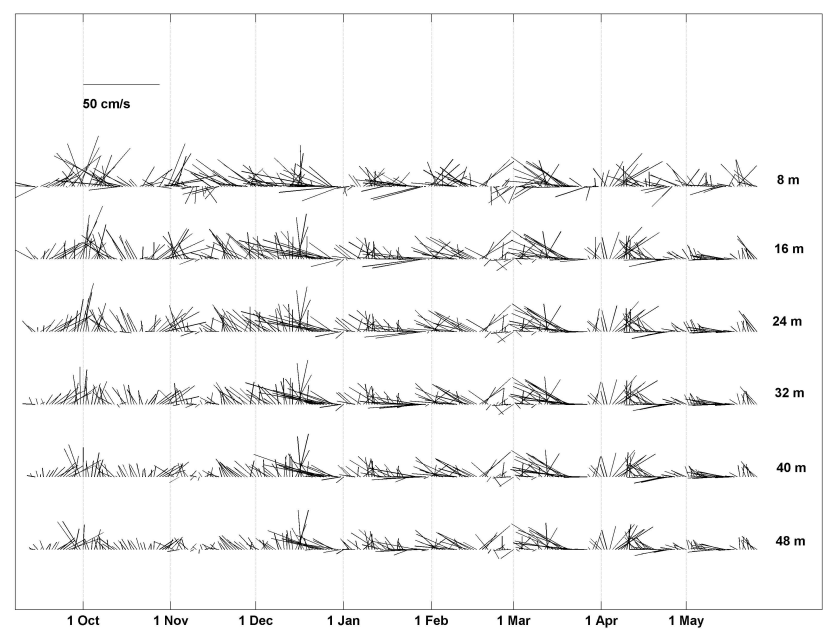

Fig. 7. Stick Diagram of daily mean data of horizontal currents from the ADCP at each level.

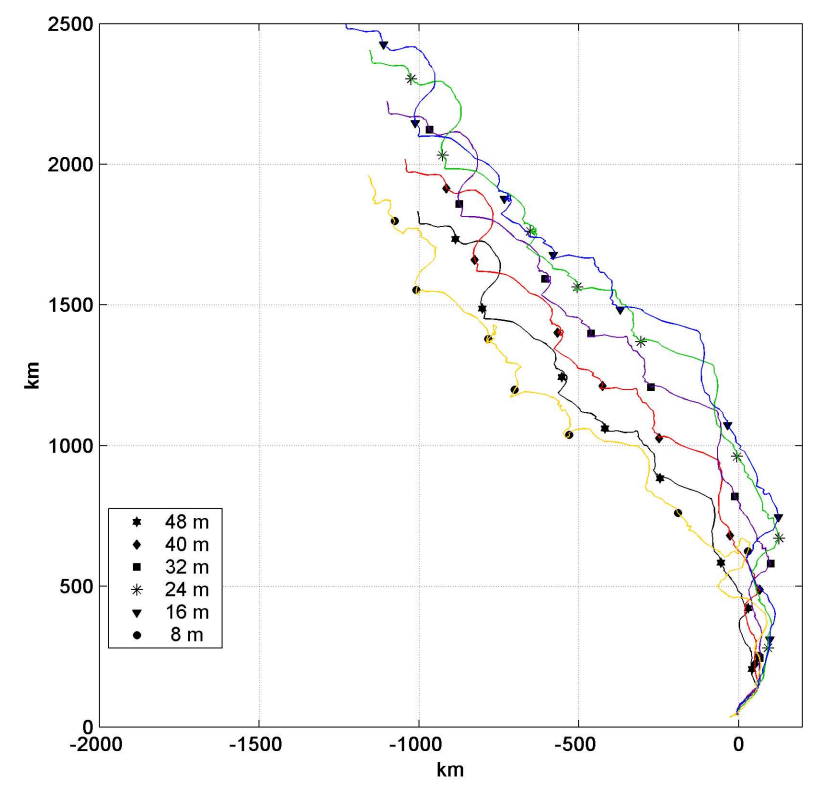

Fig. 8. Progressive Vector of daily mean data of horizontal currents from the ADCP at each level. Markers indicate the first day of each month.

at the lowest depth; standard deviation spanned from 8.3 to $4.2 \mathrm{~cm} / \mathrm{s}$. The analysis did not evidence the presence of tidal components, not even in the anticlockwise part, which was not masked by the inertial signal. Only a small relative maximum in the semidiurnal band appeared in the first layer spectrum. The depth-averaged spectrum is shown in Fig. 12. Similar results were obtained by separately analyzing the first two modes. In both cases energy was concentrated in the inertial band but the second-mode positive spectrum evidenced a small peak on the semidiurnal band, which was absent in the first-mode spectrum.

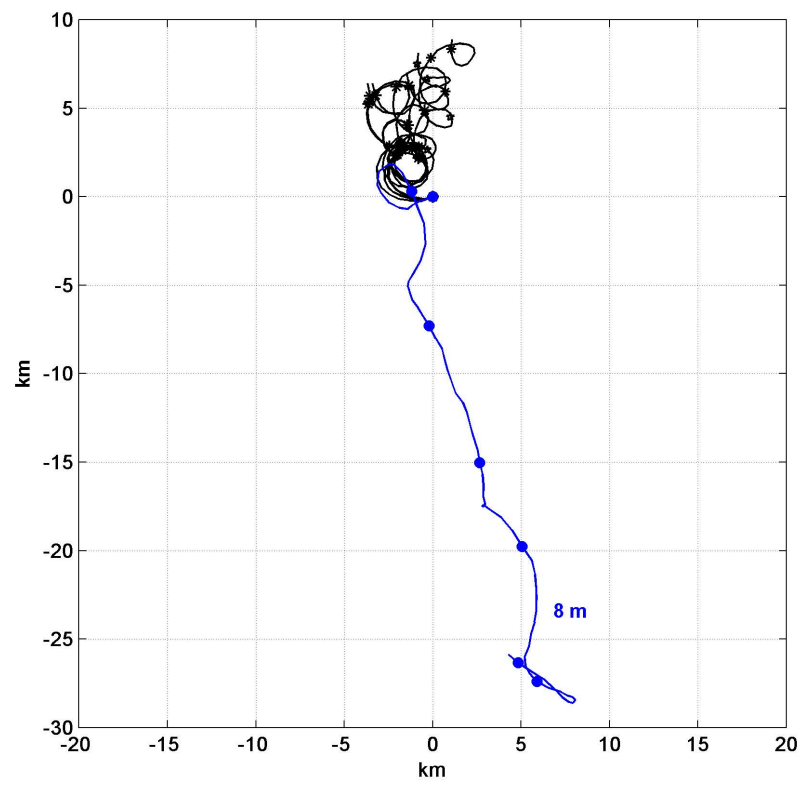

Fig. 9. Progressive Vector of hourly mean data of currents from 23rd to 25th of February 2004. Markers indicate $12 \mathrm{~h}$ intervals.

In order to detect the occurrence of inertial motions and to analyze their temporal evolution, time-dependent complex frequency analysis was performed on the time series. The spectrogram was obtained using a $256 \mathrm{~h}$ sliding window with $255 \mathrm{~h}$ overlap between each sample; a $256 \mathrm{~h}$ window Hanning filter was applied to the resulting time series. The time evolution of the energy in the inertial band (5.6413$6.031910^{-2} \mathrm{cph}$ ) was then extracted (Fig. 13). Inertial oscillations were observed during the whole period of measurements. They occurred in bursts lasting up to several days and were better developed in autumn: the most persistent and energetic were observed from 20th of November 2003 to 6th of December 2003. The mean amplitude of inertial currents was about $10 \mathrm{~cm} / \mathrm{s}$, comparable with that of the mean flow. During autumn energy was higher at the lower levels and it was consistent with the mixed-layer formation; during the rest of the period it reached the maximum value at surface and it was attenuated with depth.

To investigate lower frequencies, spectral analysis was also performed on longer samples (512 and 1024 days) but, due to the limited length of the time series, the confidence interval increased. Red-spectrum was a dominant feature; the energy was more concentrated in the clockwise component of the spectrum and in the low-frequency components. In addition to the dominant inertial peak, the analysis indicated some energy also on $80 \mathrm{~h}$ and $95 \mathrm{~h}$ in the positive side of the spectrum. 

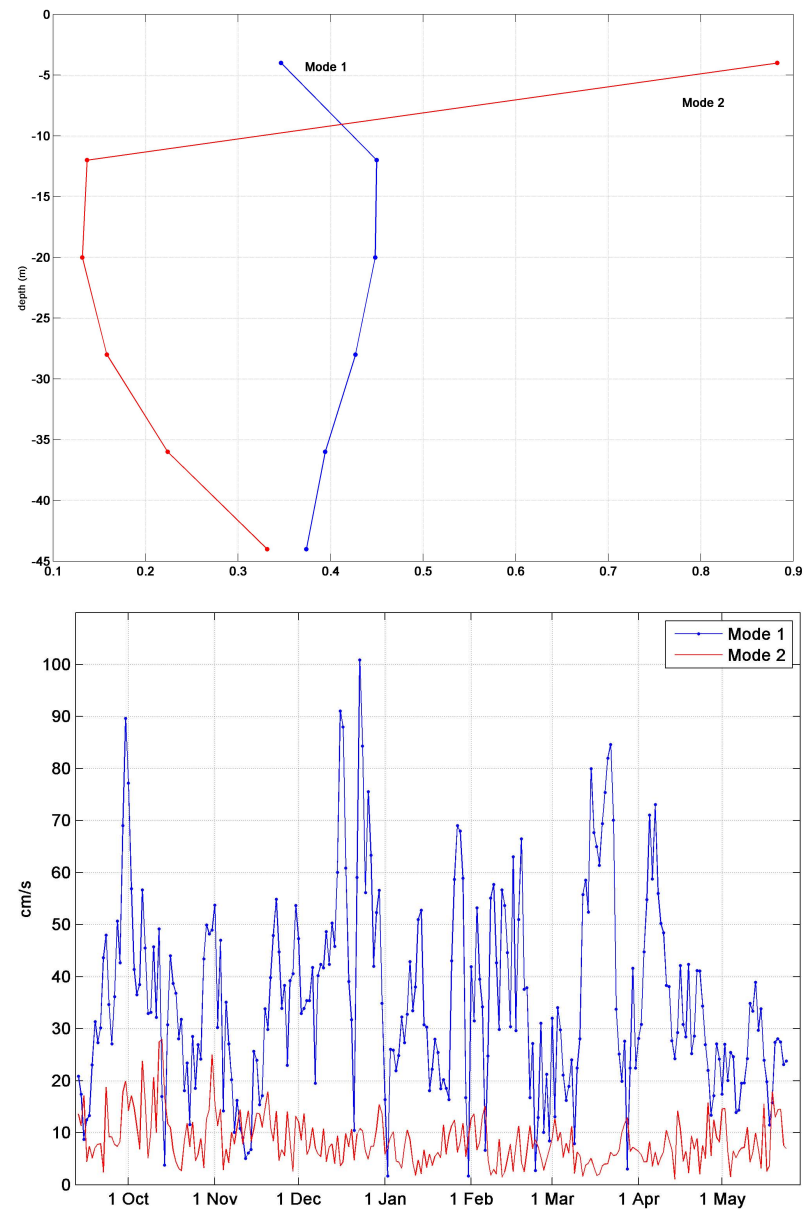

Fig. 10. Complex EOF decomposition of daily mean time series of ADCP currents: magnitude of first two modes profiles (a) and temporal series of coefficients (b).

\subsection{Vertical velocities}

Vertical velocities structure was characterized by intermittent bursts of oscillations reaching the amplitude of few centimetres per second (up to $10 \mathrm{~cm} / \mathrm{s}$ in the upper layer). These episodes generally lasted about 2-4 days and interested the entire sampled water column, but the amplitude attenuated with increasing depth (Fig. 14). As well as the horizontal currents, also the vertical components were highly correlated: correlation coefficient spanned from 0.56 to 0.97 .

The power spectrum was white with well defined peaks on the diurnal and sub-diurnal bands. The predominant frequency corresponded to $0.0147 \mathrm{cpd}$ (diurnal cycle), determined by the daily migration of scattering organisms, while the signal the inertial frequency was very weak. As suggested by previous work (Van Aken et al., 2007) this is not surprising as this motion is predominantly horizontal. Other peaks related to internal waves - in particular on 8 and $6 \mathrm{~h}-$ were detected, but these events were too brief and their frequency too variable to obtain a good spectral resolution.

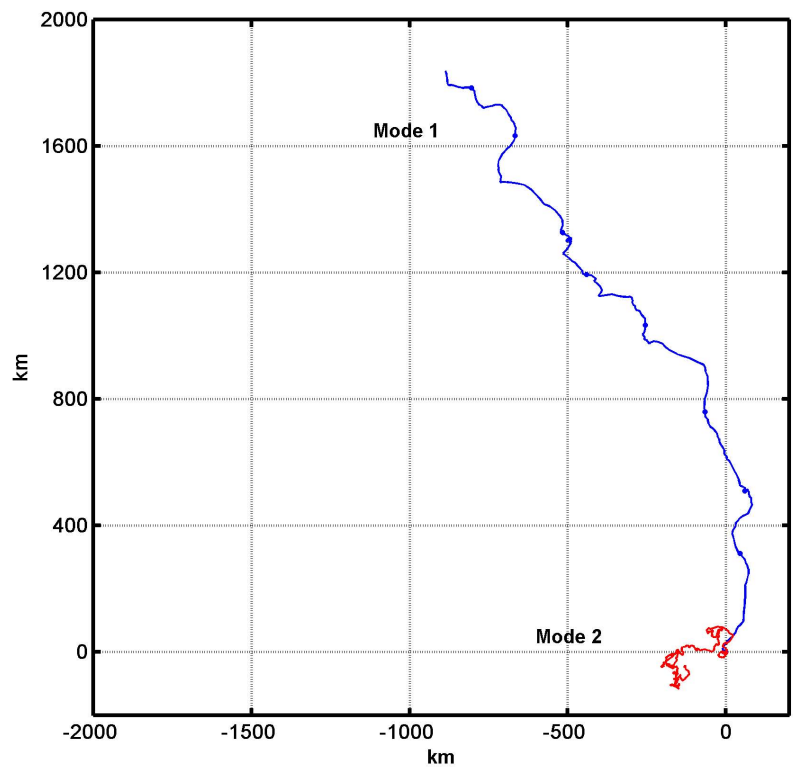

Fig. 11. Progressive Vector of the first two EOF modes currents in the upper layer. Markers indicate the first day of each month.

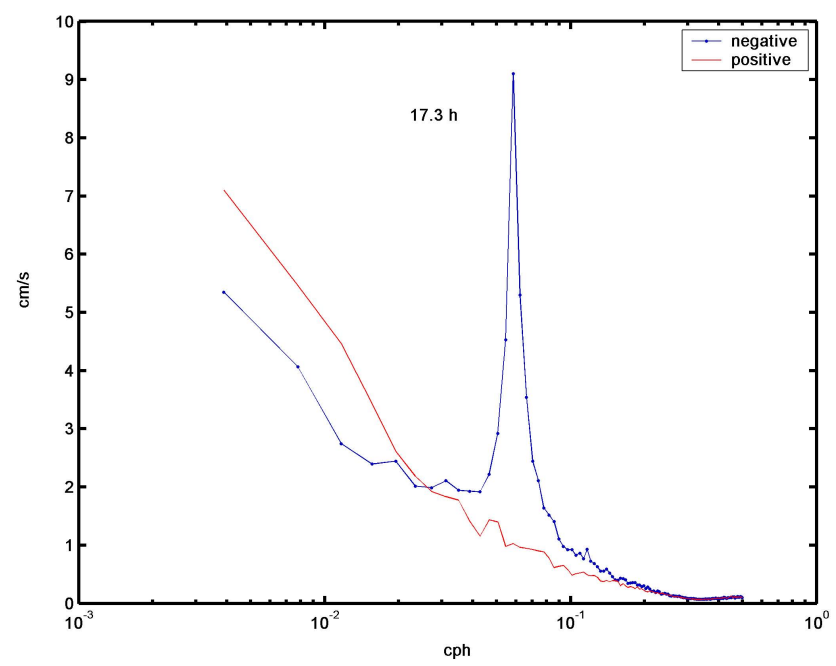

Fig. 12. Vertically averaged rotary spectrum of hourly mean currents.

The investigation of the time-spectral characteristics related to the observed oscillations, has been performed following the methodology proposed by Jacobs et al. (2001). The data contained in a 4-day moving window were fit by least square method with a function consisting in a linear trend and a combination of cosine and sine wave. A relatively fine frequency discretization ( $d f=0.025 \mathrm{cpd}$ ) was used to span the band from 2 to $6 \mathrm{cpd}$; the temporal resolution was determined using a 3-day overlapping window. The resulting spectrogram (Fig. 15) confirmed the episodic nature of the observed oscillations whose energy was spread over the whole frequency range with a weak concentration on $2.8 \mathrm{cpd}$ 


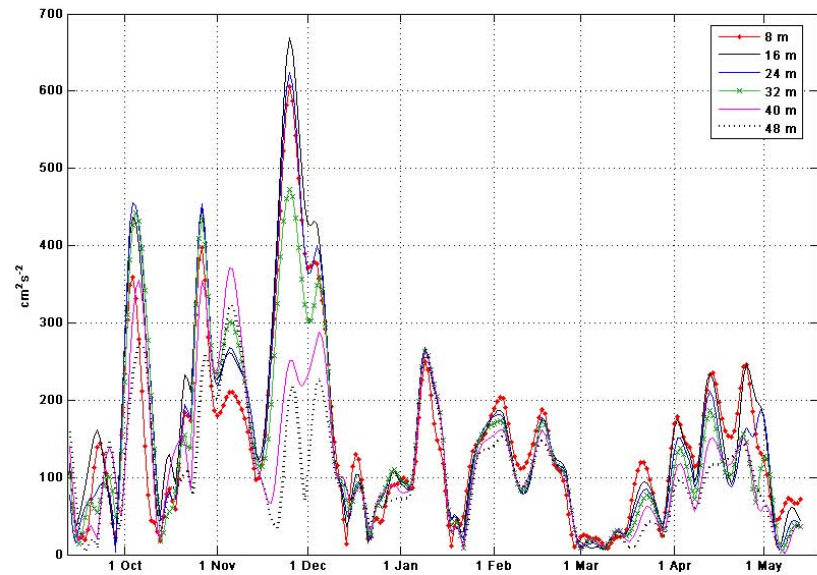

Fig. 13. Smoothed time series of energy on the inertial band (5.64$6.0310^{-2} \mathrm{cph}$ ) extracted from the spectrogram at each level.

and $5.5 \mathrm{cpd}$ waves, roughly corresponding to a period of 9.6 and $4.3 \mathrm{~h}$. The range of frequency (higher than the local inertial frequency) of these perturbations and their attenuation with the depth suggest the presence of downward propagating internal waves.

\section{Local wind and currents}

Currents in the near surface layer have shown in several cases a different pattern from the layers below. Preliminary considerations indicate the wind as the main responsible factor for such variability (Wang and Huang, 2004). The availability of surface meteorological observation from the ODAS Italia 1 buoy allowed investigating the role of local forcings on the surface circulation. The relation between local wind and surface currents was investigated by using the second EOF mode time series, which described the near-surface variability. This choice was also supported by the complex correlation analysis between daily mean wind and surface current. Results showed that the correlation coefficient increases from 0.31 and $25^{\circ}$ angle to 0.62 and $11^{\circ}$ angle when the analysis is performed on the second mode current instead of on the entire signal.

To estimate the effects of the wind on the surface circulation, numerical tests were performed with a simple numerical model, integrating the Ekman equations reported below.

$$
\left\{\begin{array}{l}
\frac{\partial u}{\partial t}-f v=A_{v} \frac{\partial^{2} u}{\partial z^{2}} \quad t \geq 0 ; H \leq z \leq 0 \\
\frac{\partial v}{\partial t}+f u=A_{v} \frac{\partial^{2} v}{\partial z^{2}}
\end{array}\right.
$$

$$
\begin{aligned}
& -A_{v} \frac{\partial u}{\partial z}=\frac{\tau_{x}}{\rho w} \quad \text { at the surface } \\
& -A_{v} \frac{\partial v}{\partial z}=\frac{\tau_{y}}{\rho w} \\
& u=0 \\
& v=0
\end{aligned}
$$

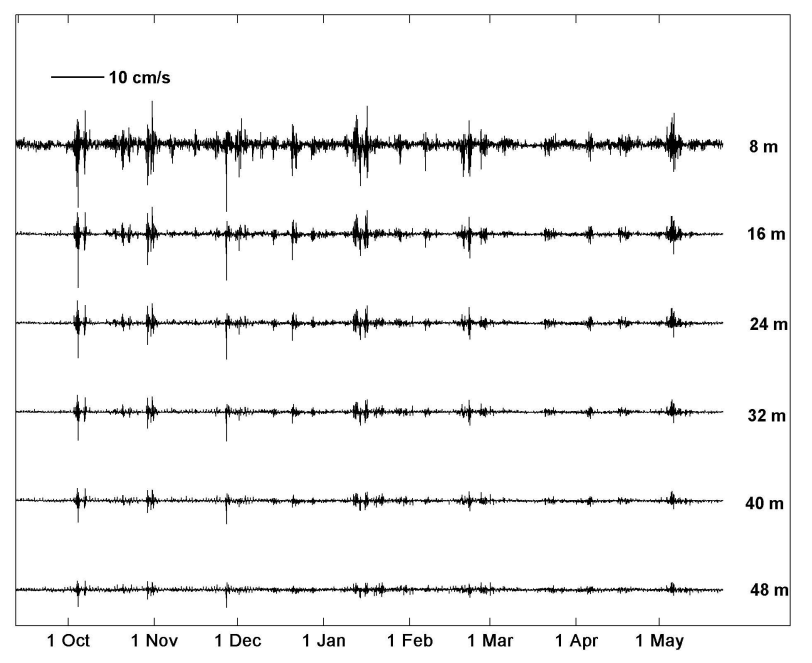

Fig. 14. Hourly data of vertical currents at each level.

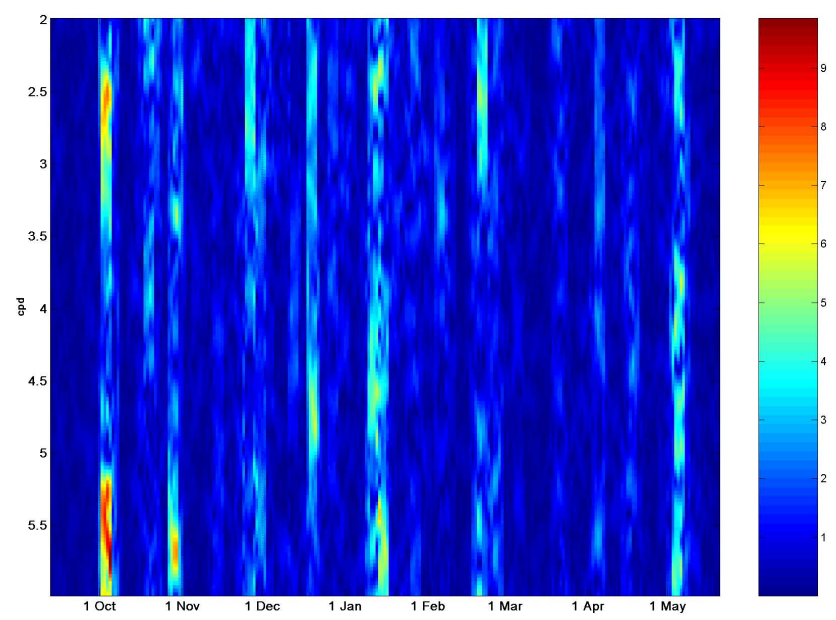

Fig. 15. Time/frequency distribution of vertical currents amplitude at $16 \mathrm{~m}$ depth.

Where $u$ and $v$ are the horizontal components of current, $H$ is the column depth, $\tau$ is the wind stress, $f$ is the Coriolis parameter, $\rho_{w}$ is the water density and $A_{v}$ is the turbulence diffusivity. No-slip conditions were imposed at the bottom to simulate that the wind effect vanishes at a finite depth.

Wind stress $(\tau)$ was computed according to Fairall et al. (1996) by using the available data acquired by the buoy.

It was assumed $H=100 \mathrm{~m}, A_{v}=0.01 \mathrm{~m}^{2} \mathrm{~s}^{-1}, f=$ $10^{-4} \mathrm{~s}^{-1}$. Under these conditions the resulting Ekman depth $\sqrt{2 A_{v} / f}$ is $14 \mathrm{~m}$. Numerical simulations were performed starting from rest conditions and assuming a vertical resolution of $4 \mathrm{~m}$ and a time step of $600 \mathrm{~s}$, to ensure the numerical stability. For these simulations the entire time series of wind stress resampled at the appropriate temporal step (600 s) was used. 

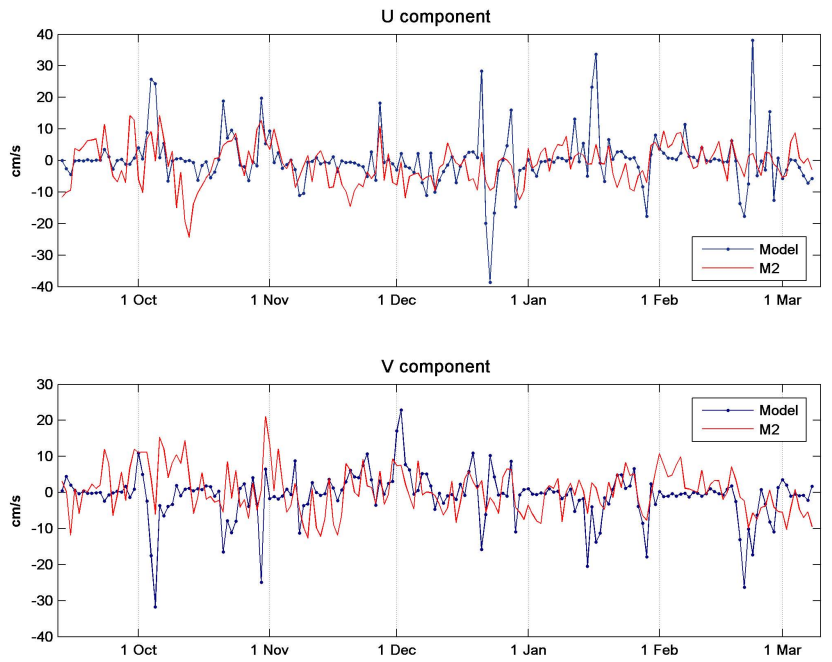

Fig. 16. Comparison of simulated and second mode surface currents: daily mean $u$ and $v$ component.

Results of simulations were vertically averaged in order to obtain the same vertical resolution of the ADCP and were compared with the second mode currents time series. Though the model results showed a higher standard deviation $(12.7 \mathrm{~cm} / \mathrm{s}$ with respect to $9.1 \mathrm{~cm} / \mathrm{s})$, mean intensity of simulated and second mode currents were quite similar (about $10 \mathrm{~cm} / \mathrm{s})$ and they were both directed to the South $\left(167^{\circ} \mathrm{N}\right.$ and $240^{\circ} \mathrm{N}$ ). Main differences between model and observations, as shown in Fig. 16, were due to the response of the currents when strong winds blow. The second mode currents were not significantly affected by such events, neither in correspondence of the strong wind episodes of 22nd of December 2003, 17th of January 2004 and 22nd of February 2004, when high wind-driven currents resulted from the model. Strong winds in the Ligurian Sea are often associated to large-scale atmospheric circulation, so that the oceanic response to time dependent atmospheric forcings at periods between a few days and a few hundred days is essentially depth independent (Willebrand et al., 1980; Gasparini and Manzella, 1984). A better correspondence between the observation and the model output was found with low wind regime as evidenced in Fig. 17, which reports a sample of the hourly mean values of simulated and observed $u$ and $v$ currents components from 1st of November 2003 to 17th of December 2004.

The rotary spectra of observations and model results, averaged on $256 \mathrm{~h}$ long samples, had similar characteristics (Fig. 18). In both the spectra the inertial peak dominated and some energy in the low-frequency band was observed. Inertial simulated currents were higher than the observation, $7 \mathrm{~cm} / \mathrm{s}$ and $5 \mathrm{~cm} / \mathrm{s}$ respectively, probably because of the model response to the high wind stress.

These numerical tests explained part of the variability observed in the near-surface currents and indicated the minor
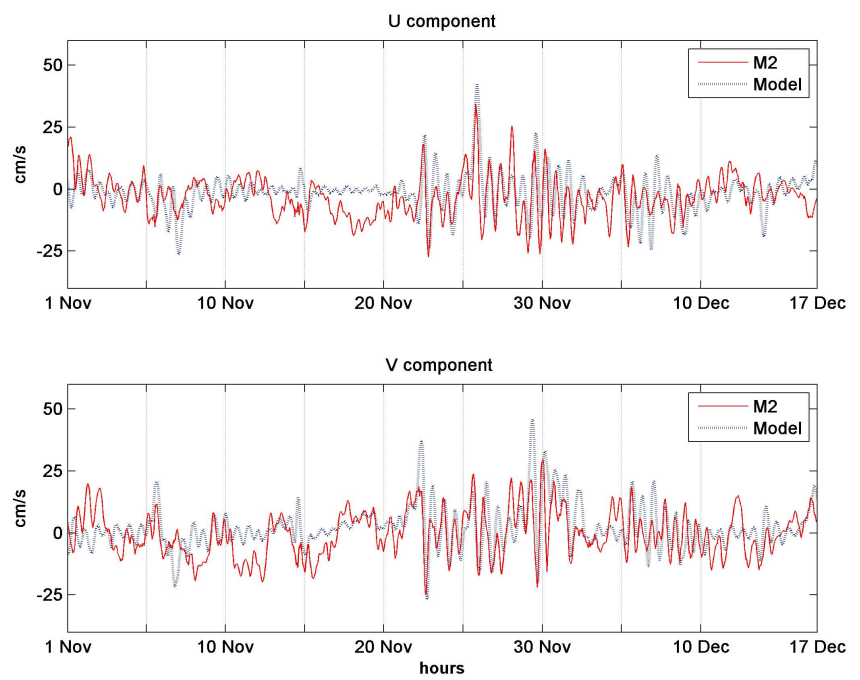

Fig. 17. Comparison of simulated and second mode surface currents: hourly mean $u$ and $v$ component from 1st of November 2003 to 17 th of December 2003.

role of the wind-driven currents with respect to the general barotropic circulation.

\section{Discussions}

In order to investigate the dynamics of the upper layer and its variability in response to the local atmospheric forcings, surface current observations from an upward looking ADCP moored in the Central Ligurian Sea and meteo-marine parameters from a fixed offshore buoy, as well as numerical simulations with 1-d Ekman model, were used.

The vertical structure of the currents in the upper thermocline can be described as a barotropic layer moving NorthWest at a mean speed of $17.5 \mathrm{~cm} / \mathrm{s}$. Main differences in the pattern, in particular the occurrence of southward currents, were confined to the near-surface layer. The observed northeast meandering can be explained as pulses of the mean flow, as suggested by Sammari et al. (1995) analyzing the Northern Current.

Time-frequency analysis revealed that the main variability was determined by the inertial currents. They had a magnitude comparable with the mean velocity and were detected at all depths. They occurred intermittently during the whole period of measurements and each time they lasted several days. The more energetic currents were found during autumn, while during winter their amplitude was reduced. The analysis of current time series did not reveal a clear relationship between the onset of inertial currents and strong wind events, except for the episode occurred on 6th of October, when the thermocline was still well developed.

Inertial oscillations are very common in the ocean. They can be locally generated at the surface by changes in wind 


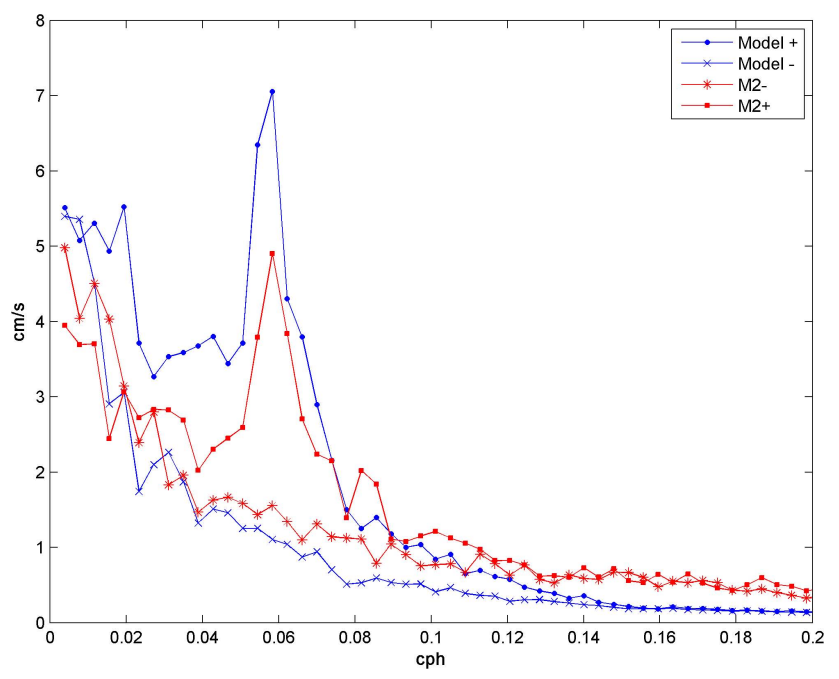

Fig. 18. Comparison of simulated and second mode surface currents: rotary spectrum.

stress or by the rapid transit of a low pressure system and can persist for several days. These oscillations propagate energy far from the area of generation as well as downward in the water column, generating higher-frequency internal waves through non linear interactions (D'Asaro, 1985; Petrenko, 2003; Plueddelmann and Farrar, 2006). The existence of mixed layer inertial currents unrelated to wind forcing was reported by different authors. Van Haren and Millot (2003) found similar results in the Ligurian Sea and underlined the important role of the thermal stratification of waters in the vertical propagation. For their contribution to the mixing, inertial waves play a fundamental role in regions such as the Ligurian Sea, since they compensate the lack of the tidal mixing.

In order to investigate the role of local wind, a complex EOF decomposition of current ADCP profile and the application of time dependent Ekman model were performed. Although the physical interpretation of the modes is not always clear (Borzelli and Ligi, 1999), this method has proved to be an efficient tool to separate different characteristics of the circulation. The first mode was used to investigate the dominant large-scale circulation. The second mode evidenced the variability confined to the near-surface layer and was considered appropriate to study the effects of the local wind stress. Wind-driven currents gave a minor contribution to the surface circulation of the area, nevertheless, in few cases, were comparable to the large scale component. The computed Ekman currents, on the average, were consistent with the second mode current, even if the model overestimated the effects of strong wind episodes. These events are associated to the large scale atmospheric variability and in the Ligurian Sea this forcing affects the general barotropic cyclonic circulation.
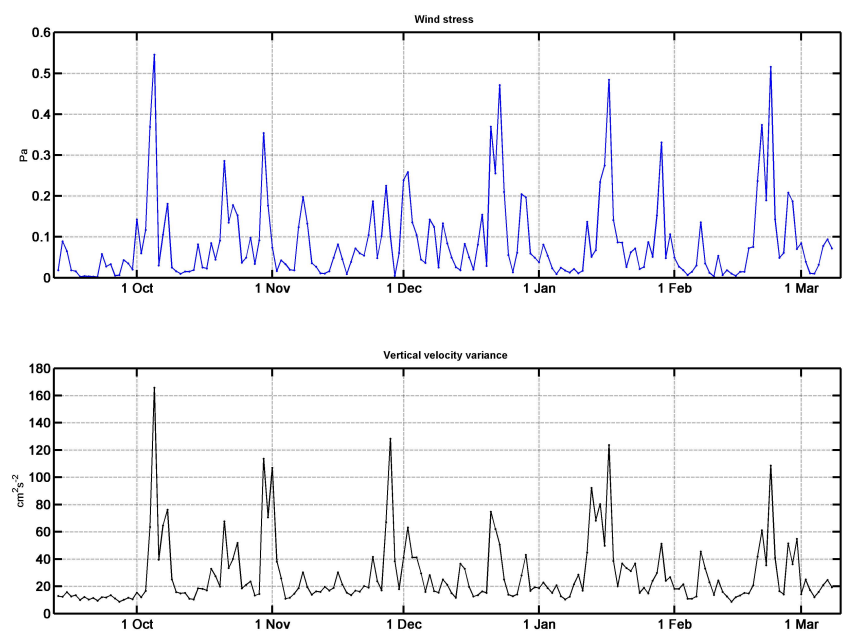

Fig. 19. Time series of daily mean wind stress magnitude and vertical velocities standard deviation.

Moreover, it was evidenced a nearly one-to-one correspondence between the wind stress relative maximum and the occurrence of vertical oscillations, identified by a maximum of daily standard deviation (Fig. 19). Their amplitude damped with the depth and did not show a clear relation with the intensity of wind stress nor to the vertical stratification; a more comprehensive analysis on their origin and contribution to the vertical mixing would require longer time series. The vertical thermal structure in the upper thermocline displayed a high variability related to the presence of the Ligurian front, the occurrence of internal waves and the wind mixing. Such variability can be taken into consideration when approaching air-sea interaction studies in this area.

Acknowledgements. The content of this paper is based on the presentation held at the Conference "Rapid Environmental Assessment (REA)", Lerici (Italy), 25-27 September 2007. The authors are grateful to Mireno Borghini, CNR ISMAR La Spezia, which was responsible for the oceanographic measurements. Thanks are due to the captain and the crew of N/O URANIA for the support during at sea operations.

Edited by: E. J. M. Delhez

\section{References}

Astraldi, M. and Manzella, G. M. R.: Some observations on current measurements on the Eastern Ligurian Shelf, Mediterranean Sea, Cont. Shelf Res., 2, 183-193, 1983.

Astraldi, M., Gasparini, G. P., Manzella, G., and Hopkins, T. S.: Temporal variability of currents in the Eastern Ligurian Sea, J. Geophys. Res., 95(C2), 1515-1522, 1990.

Astraldi, M. and Gasparini, G. P.: The seasonal characteristics of the circulation in the North Mediterranean basin and their relationship with the atmospheric-climatic conditions, J. Geophys. Res., 97(C6), 9531-9540, 1992. 
Birol, F., Cancet, M., and Estournel C.: Aspects of the seasonal variability of the Northern Current (NW Mediterranean Sea) observed by altimetry, J. Mar. Syst., 81 297-311, 2010.

Borzelli G. and Ligi R.: Empirical Orthogonal Function Analysis of SST Image Series: a Physical Interpretation, J. Atmosph. Ocean. Tech., 16, 682-781, 1999.

Björnsson, H. and Venegas, S. A.: A manual for EOF and SVD analyses of climatic data, Technical report, Department of Atmospheric and Oceanic Sciences and Centre for Climate and Global Change Research, McGill University, 52 pp, 1995.

Cappelletti, A., Picco, P., and Peluso, T.: Upper ocean layer dynamics and response to atmospheric forcing in the Terra Nova Bay polynya, Antarctica, Antarctic Science, 22, 319-329, 2010.

D'Asaro, E. A.: The Energy Flux from the Wind to Near-Inertial Motions in the Surface Mixed Layer, J. Phys. Oceanogr., 15, 1043-1059, 1985.

Edwards, C. R. and Seim, H. E.: Complex EOF Analysis as a Method to Separate Barotropic and Baroclinic Velocity Structure in Shallow Water, J. Atmosph. Ocean Tech., 25, 808-821, 2008.

Emery, W. J. and Thomson, R. E.: Data Analysis Methods in Physical Oceanography, Elsevier Science B.V., 638 pp., 2001.

Fairall, C. W., Bradley, E. F., Rogers, D. P., Edson, J. B., and Young, G. S.: Bulk parameterization of air-sea fluxes for Tropical Ocean-Global Atmosphere Coupled-Ocean Atmosphere Response Experiment. J. Geophys. Res., 101(C2), 3747-3764, 1996.

Jacobs, G. A., Book, J. W., Perkins, H. T., and Teague, W. J.: Inertial oscillations in the Korea Strait, J. Geophys. Res., 106(C11), 26943-26957, 2001.

Gasparini, G. P. and Manzella, G. M. R.: The response of Ligurian Sea to large scale atmospheric fluctuations, Oceanol. Acta, 7, 4953, 1984.

Gonella, J.: A rotary-component method for analyzing meteorological and oceanographic vector time series, Deep-Sea Res., 19, 833-846, 1972.

Hisaki, Y.: Analysis of decomposed surface currents in a limited area, IEE J Ocean. Engineer., 31, 768-778, 2006

Millot, C.: Circulation in the Western Mediterranean Sea, Oceanol. Acta 10, 143-149, 1987.

Millot, C.: Mesoscale and seasonal variabilities of the circulation in the Western Mediterranean, Dynam. Atmos. Oceans, 15, 179214,1991

Ovchinnikov, I. M.: Circulation in the surface and intermediate layers of the Mediterranean, Oceanology, 6, 48-59, 1966.
Petrenko, A.: Variability of circulation features in the Gulf of Lion NW Mediterranean Sea, Importance of inertial currents, Oceanol. Acta, 26, 323-338, 2003.

Plueddemann, A. J. and Farrar, J. T.: Observations and models of the energy flux from the wind to mixed-layer inertial currents, Deep-Sea Res. Pt. II, 53, 5-30, 2006.

Picco, P., Bozzano, R., Schiano, M. E., Bordone, A., Borghini, M. Di Nallo, G., Schirone, A., and Sparnocchia, S.: Marine Observing Systems from fixed platforms in the Ligurian Sea, B. Geofis. Teor. Appl., 48, 227-240, 2007.

Sammari, C., Millot, C., and Prieur, L.: Aspects of the seasonal and mesoscale variabilities of the Northern Current in the western Mediterranean Sea inferred from the POLIG-2 and PROS-6 experiments, Deep-Sea Res.Pt. I, 42, 893-917, 1995.

Schott, F. and Leaman, K. D.: Observation with Moored Acoustic Current Profilers in the Convection Regime in the Golfe du Lion, J. Phys. Oceanogr., 21, 558-574, 1991

Sournia, A., Brylinski, J. M., Dallot, S., Le Corre, P., Leveau, M., Prieur, L., and Froget, C.: Fronts hydrologiques au large des cotes francaises : Les sites-ateliers du programme Frontal, Oceanol. Acta, 13, 4, 413-438,1990.

Sparnocchia, S., Schiano, M. E., Picco, P., Bozzano, R., and Cappelletti, A.: The anomalous warming of summer 2003 in the surface layer of the Central Ligurian Sea (Western Mediterranean), Ann. Geophys., 24, 443-452, 2006, http://www.ann-geophys.net/24/443/2006/.

Van Aken, H. M., Van Haren, H., and Maas, L. M. R.: The highresolution vertical structure of internal tides and near-inertial waves measured with an ADCP over the continental slope in the Bay of Biscay, Deep-Sea Res. Pt. I, 54, 533-556, 2007.

Van Haren, H. and Millot, C.: Seasonality of internal gravity waves kinetic energy spectra in the Ligurian Basin, Oceanol. Acta, 26 , 635-644, 2003.

Vignudelli, S., Cipollini, P., Astraldi, M., Gasparini, G. P., and Manzella, G.: Integrated use of altimeter and in situ data for understanding the water exchanges between the Tyrrhenian and Ligurian Seas, J. Geophys. Res., 105, C8, 19649-19663, 2000

Visbeck, M. and Fischer, J.: Sea surface conditions remotely sensed by upward-looking ADCPs, J. Atmosph. Ocean Tech., 12, 141149, 1995.

Wang, W. and Huang, R. X.: Wind Energy input to the Ekman Layer, J. Phys. Oceanog., 34, 1267-1275, 2004.

Willebrand, J., Philander, S. G. H., and Pacanowski, R. C. The Oceanic Response to Large-Scale Disturbances, J. Phys. Oceanogr., 10, 411-424, 1980. 